\title{
PRECISION CROP MONITORING FOR SUGARCANE AND CORN
}

Khan Mohd.Haris ${ }^{1}$, Sachin Kumar $^{2}$, Sumita Mishra ${ }^{3} \&$ Pragya $^{4}$

Abstract-India is an agrarian country and more than 60 percent of population depends on the agriculture for their livelihood. Agriculture is the main source of income for major part of country's population. Crops ranging from medicinal to cereal are produced in India. Owing to continuous requirement of increase in production and in-order to maintain balance between demand and supply, it is imperative that crop damage is minimized. This gave rise to demand for various technologies for crop monitoring. These include identification dry or wet field, insect attack, weed or fungal infestation or weather related damages. Continuous monitoring by an individual is not possible and to reduce this burden diversified real time monitoring systems have been developed to do the job. This paper presents a generalized system model for crop monitoring, the proposed model consist of Raspberry pi, Arduino mega 2560, Zigbee and sensors such as temperature sensor, soil moisture sensor and Humidity sensor. Further it also summarizes various crop monitoring techniques that have evolved during last decade.

Keywords- Wireless Sensors,Arduino,Raspberry Pi,Zigbee.

\section{INTRODUCTION}

Agriculture forms the backbone of most of the developing countries; in India it contributes 16.11 percent of GDP and 10 percent of export. Agriculture plays a vital role in boosting nation's economy. About 58 percent of the rural households depend on agriculture as their primary source of livelihood. As per the statistics provided by Central Statistics Office (CSO) the percentage share of agriculture and allied sector was 17 percent of gross value added (GVA) during 201617[1].(Reference. As per the 3 advance estimate India's food grains production has marginally increased to 252.23 million tonnes (MT). Indian agrochemical industry is expected to grow at 7.5 percent annually to reach US $\$ 6.3$ Billion by 2020 with domestic demand growing at 6.5 percent per annum and export demand at 9 percent per annum. India is an agricultural country which produces various types of crops, fruits, vegetables etc in large quantities. Taking into consideration the increase in population this demand is ever increasing.

Agriculture methods with smart algorithms need to be implemented to meet current and future requirements of crops.Smart agriculture utilizes technology to limit resources and to increase productivity of crops in safe and secure environment. Sensors, Control Unit (Arduino), Zigbee, Raspberry pi and Image processing algorithms generally form functional blocks of smart agriculture solutions. This aids farmers in a real time monitoring of a crop growth. Identification of disease leads to early initiatives against possible damages to crops. Figure 1 depicts major crops being produced in India. These can be broadly divided into four categories.

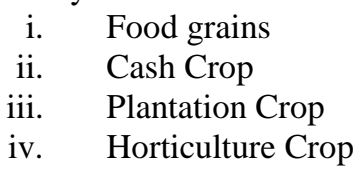

The disease rate in Sugarcane and corn crops are very high, therefore proper measures are required to be taken well in time for fruitful production.

- Sugarcane: Sugarcane belong to Bamboo family of plants and is indigeneous to India. It's an important cash crop cultivated in tropical and sub-tropical region around the world. Most of the world's sugarcane is grown between $22^{\circ} \mathrm{N}$ and $22^{\circ} \mathrm{S} .72$ percent of the land under sugarcane in India lies in U.P, Bihar, Punjab, Haryana, Rajasthan etc. Sugarcane produces raw material such as White sugar,Jaggery(gur) and khandsari. In India, with the help of sugarcane reeds people made pens, screen, Mats and thatch. Sugarcane shares $7 \%$ of the total agriculture production in India.

\footnotetext{
${ }^{1}$ Amity University Lucknow Campus

${ }^{2}$ Amity University Lucknow Campus

${ }^{3}$ Amity University Lucknow Campus

${ }^{4}$ MVPG College, Lucknow
} 
- Corn: It is one of the most important cereal crop and contributes a lot to food security in most of the developing countries. Corn is one of the most functional crop accomaditing under varied agro-climatic conditions. Corn has an ability for being cultivated in variety of soils ranging from loamy sand to clay loam. In India after rice and wheat, Corn is emerging as the third most important crop.owing to increase in demand in poultry, livestock sectors etc. To meet these demands, enhancement in corn production is a big challenge in the era of climate change. Corn shares $9 \%$ of the total agriculture production in India.The Major states producing Corn are: Karnataka, Andhra Pradesh, Maharashtra, Bihar, Gujarat, Tamil Nadu, and Rajasthan.

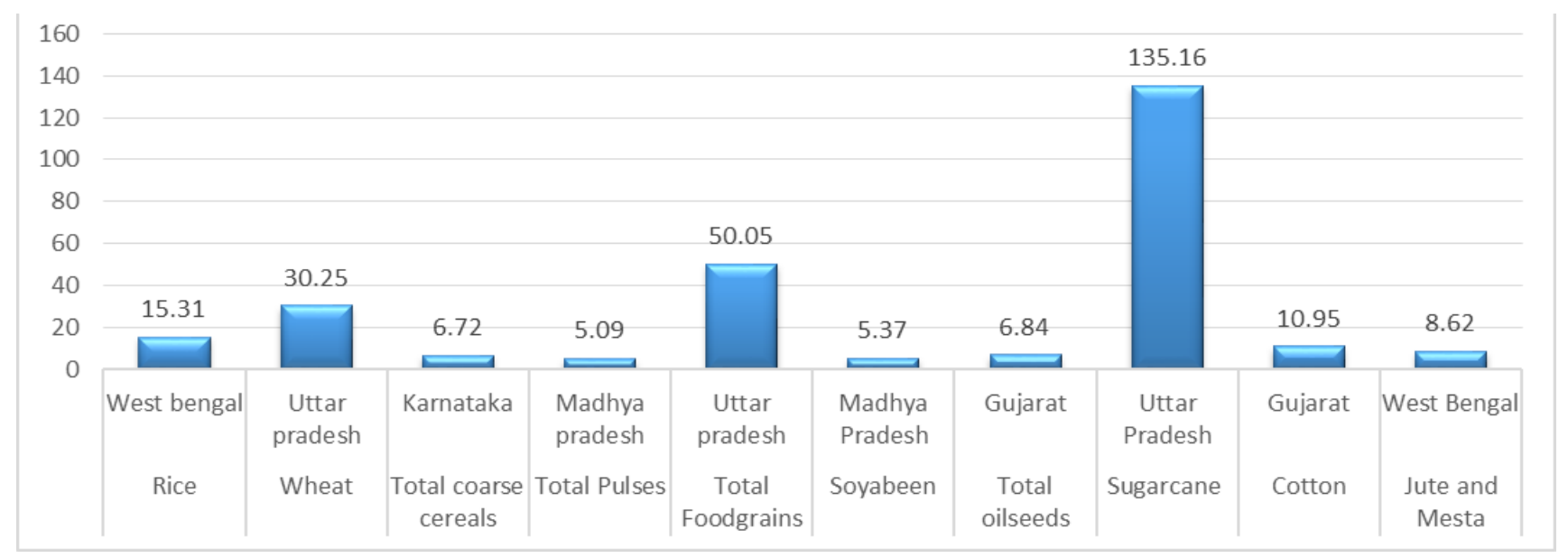

Figure 1: Major Crops in India

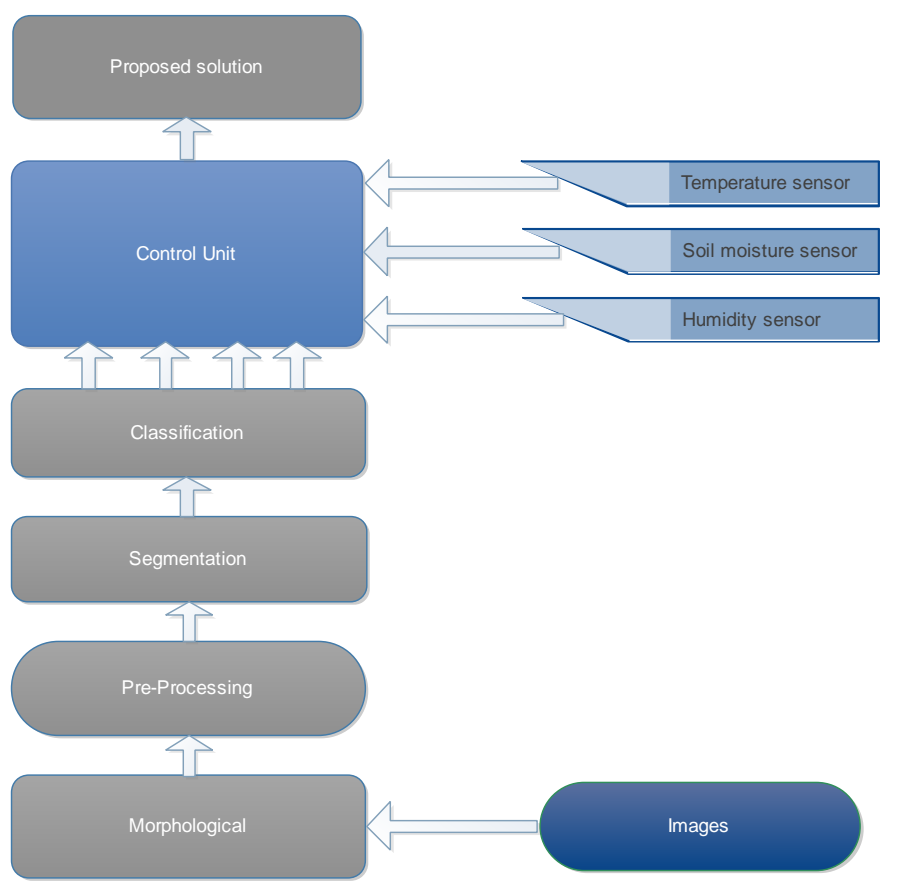

Figure 2: System Model

Figure 2 depicts generalized block diagram for crop health monitoring. The proposed system model consists of a Control unit (Arduino mega 2560) interfaced with three sensors i.e. Temperature sensor, Soil moisture sensor and Humidity sensor. Sensor interfaced with Arduino Mega 2560 interprets the values sensed by the three sensors using optimized algorithms already burnt in Arduino Board. The data collected is transferred using ZigBee to Central Processing Unit ( Raspberry pi(model B)). Readings are monitored and displayed on Raspberry pi board's display panel; so that optimum measures can be taken on divergence from ideal values, required for healthy growth of crop. The ideal temperature for healthy growth is $37^{0}$. DHT22 is used to monitor parameters humidity and temperature and EDC-274921 is used monitor soil moisture. CPU apart from monitoring ideal conditions for healthy growth, CPU also keeps a track on diseases that might infect the crop, this is 
achieved with image processing and classification algorithms. Infection is monitored and accordingly measures are suggested during different growth cycles of the growth.

\section{RELATED STUDY}

There has been a lot of work been done in the area of crop monitoring but owing to the importance and potential involved through progress in technology, a lot more can be achieved. Over the period diversified methods have been employed for smart agriculture this is summarized in Table 1.

Sudhanshu Sekhar Panda et al developed an algorithm which is helpful in studying corn crop yield estimation for irrigated land from PVI, a distance based technique which is a better technique as compared to other three spectral indices i.e. GVI, NDVI and SAVI [21], Wagner in 2010 basically developed a Remote sensing methodology with the help of sensors to increase the growth rate of sugarcane. Khistij et al developed an algorithm Using intelligent humidity sensor that reduced power consumption and data processing by 50 per-cent [1], further one of the papers suggested utilization of WSN technology to detect abnormalities, the algorithms used sensor nodes to collect physiological indexes and transmitted the data to the local computer. This utilization of sensor data base and real time report was conducted in a low powered embedded system, this was suggested by D. Mahesh Kumar in his publication.[23]. Amol D Vibhute and Dr. Bharti W Gawali developed a prototype consisting of RS, GIS and GPS technology with maximum likelihood classification technique a supervised classification technique to achieve greater accuracy compared to known literature[13], Anjum Awasthi et al proposed a system for sugarcane crop production in Indian climatic condition with the help of WSN for information acquisition, and structuring by wireless sensor node with base station for recording the data of sensor nodes. El_Hag et al developed a prototype which continuously monitor the sugarcane crop and further it explained the increase and decrease in fields effect environmental factor, slope, water distribution system and agriculture cycles. Layout of the four maps for each area was produced by unsupervised classification without being in contact with the study area. [19], Umapathy Eaganathan et al developed an algorithm for the identification of sugarcane leaf scorch disease using image processing algorithms in which leaf surface were extracted from RGB images which were converted to $\mathrm{L}^{*} \mathrm{a} * \mathrm{~b}$ to detect disease accurately in colour model L*a*b utilizing K-means algorithm K-NN classifier[6], N. Sakthipriya developed a prototype using WSN for crop monitoring in the locations which were previously inaccessible with a simplified installation and maintenance setup[16], Andrés Fernando Jiménez López et al proposed a system that had five programming languages integrated (HTML, Java script, Node.js, C++ and python) when implemented together, complemented each software tool (GPS base station, indexes platform and station telemetry) to generate a base to develop applications for civilians[15].

The red rot disease common in sugarcane can be controlled using method known as integrated disease management strategy applying biotechnological approach by supplementing control measures like quarantine regulations, clean cultural practises, use of chemicals, bio control agents and heat therapy, implying novel strategies which are not yet discovered could be useful in exploring systematic resistance against C. falcatum. This work was published by Ruchika Sharma and Sushma Tamta[5], the most common method of plant Disease detection using naked eye was replaced by automatic device monitoring system with the use of K-means Clustering of the data taken from the WSN. This was published by Vaibhavi S. Bharwad and Kruti J. Dangarwala.[4] Kirankumar Y. Bendigeri and Jayashree D. Mallapur employed Qualnet simulator for device deployment for successful monitoring of plants by checking temperature, pesticides, humidity without any human intervetion and was implemented in half acre of land as a prototype model. [17], Ruchika and Ruchi Taneja also proposed and developed a prototype employing Arduino and ARM11 based Raspberry pi through IOT(Internet of things) for sending data on real time basis in its database, that was updated every 2 seconds with automatic database updating capabilities[7].

Saleemmaleekh Attar and Sudhakar K N proposed a system that deals with precision agriculture for growing crops efficiently using low cost model with real time environmental data being transmitted to remote locations using GSM network. [22], Meeradevi, Monica et al developed a system using remote wireless devices and Wireless Sensor Networks for crop field monitoring with prototype hardware built for studying environmental parameters like temperature, humidity and soil moisture, the system developed utilized SMS to provide information to the farmers using GSM technology.[25], Tushar H. Gore et al proposed an algorithm to monitor temperature, Humidity and $\mathrm{CO} 2$ which can be monitored by streaming data from the greenhouse and can be controlled using a smartphone from a remote location[24], Bhagyashree K Chate et al developed a prototype for innovative irrigation system that provides streaming of data using Android phones with the capabilities like turning ON/OFF motor automatically, and capturing live crop images through Wi-Fi thus keeping the system entirely monitored and controlled with the help of Raspberry pi. [9], Dr.D.Devi Aruna developed an algorithm for Automatic detection of disease giving insight regarding various abnormalities seen in a sugarcane plant[8], By using WSN monitoring requirements and human effort were simplified in the fields of automatic agriculture by implementing customized environment to enhance optimal growth conditions of plants, thereby widening the use of sensors and storing the data in the cloud keeping it accessible throughout the world. This work was published by K. Lakshmisudha, Swathi hedge, Neha kale and Shruti Iyer[10], Suprabha Jadhav and Shailesh Hambarde developed a prototype with the help of Raspberry pi for Automated irrigation system which leads to a decrease in manpower, with improved water production and increased profit rate making it feasible and cost effective for agriculture production, including feedback control system to monitor and control the irrigation system efficiently[11], G.T.Hariharan et al proposed a system for feature extraction and classification techniques to study the infected leaves and its classification using self-organized feature map, back propagation algorithm 
and SVM's. [14], Manikantan Krishnaswamy Ramakrishna, Priya Prakash Parab, Puneet Girish Durve et al developed a hardware to improve energy efficiency, cost efficiency and accuracy issues in the area of agriculture in south Asia by implementing heavy economical systems integrated with GSM module and 8051 microcontroller consuming less power. [3], Deep Mala and Dr.Suhas H.Patil developed a prototype using wireless sensor network in agricultural monitoring at remote sites and reachable locations that provided improved quality and yield rate of the crop in the agricultural field thus analyzing the information to support the decision making of producers. Techniques to identify soil problem was also implemented; it also dealt with irrigation time and drought monitoring issues for healthy yield of the crop[18].

Table 1:Breif summary of Smart Agriculture

\begin{tabular}{|c|c|c|c|}
\hline Sr. No & Author's Name & Algorithm / Technology Used & Year \\
\hline 1 & $\begin{array}{ll}\text { Sudhanshu } & \text { Sekhar } \\
\text { Panda et al } & \end{array}$ & $\begin{array}{l}\text { Using neural network, Image processing, GPS and GIS modeling } \\
\text { techniques in spectral vegetation indices in crop yield prediction for } \\
\text { agricultural land. }\end{array}$ & 2010 \\
\hline 2 & Kshitij Shinghal et al & $\begin{array}{l}\text { intelligent humidity sensor reduced data processing and power } \\
\text { consumption by } 50 \%\end{array}$ & 2011 \\
\hline 3 & $\begin{array}{l}\text { Anjum Awasthi and } \\
\text { S.R N Reddy }\end{array}$ & $\begin{array}{l}\text { Used WSN in agriculture for information acquisition, and structuring } \\
\text { the agriculture monitoring system }\end{array}$ & 2013 \\
\hline 4 & $\begin{array}{l}\text { Umapathy } \\
\text { Eaganathan, et al }\end{array}$ & $\begin{array}{l}\text { Image processing algorithms along with K-means algorithm and K- } \\
\mathrm{NN} \text { classifier was used for detection. }\end{array}$ & 2014 \\
\hline 5 & N. Sakthipriyas & $\begin{array}{l}\text { The real time deployment of Wireless sensor network(WSN) } \\
\text { algorithm }\end{array}$ & 2014 \\
\hline 6 & $\begin{array}{l}\text { Andrés } \quad \text { Fernando } \\
\text { Jiménez López et al }\end{array}$ & $\begin{array}{l}\text { GPS,WSN and Image Processing for image acquisition using a } \\
\text { model helicopter which contains video cameras having a resolution } \\
\text { of } 640 \times 480 \text { pixels }\end{array}$ & 2015 \\
\hline 7 & $\begin{array}{l}\text { Kirankumar } \\
\text { Jayashree }\end{array}$ & $\begin{array}{l}\text { Used QUALNET simulator for growing plants by controlled } \\
\text { environment. }\end{array}$ & 2015 \\
\hline 8 & $\begin{array}{l}\text { Ruchika and } \\
\text { RuchiTaneja }\end{array}$ & $\begin{array}{l}\text { Used Arduino and ARM11 based Raspberry pi by sending data } \\
\text { through IOT in a real time basis. }\end{array}$ & 2015 \\
\hline 9 & $\begin{array}{l}\text { Vaibhavi S. Bharwad } \\
\text { et al }\end{array}$ & Use of K-means Clustering of the data taken by the WSN. & 2015 \\
\hline 10 & Tushar H. Gore et al & $\begin{array}{l}\text { The prototype developed which collects data from the greenhouse } \\
\text { and streaming to smart phone from a remote location. }\end{array}$ & 2016 \\
\hline 11 & Meeradevi et al & Proposed system deals with a GSM and WSN, WSN technology. & 2016 \\
\hline 12 & $\begin{array}{l}\text { Deep Mala and } \\
\text { Dr.SuhasH.Patil }\end{array}$ & $\begin{array}{l}\text { Wireless sensor network(WSN) in agricultural monitoring at remote } \\
\text { sites }\end{array}$ & 2016 \\
\hline 13 & G.T.Hariharan et al & $\begin{array}{lllll}\text { Using Image processing self-organized } & \text { feature } & \text { map, back } \\
\text { propagation algorithm and SVM's. } & & & \end{array}$ & 2016 \\
\hline 14 & $\begin{array}{l}\text { Amol D Vibhute and } \\
\text { Dr.Bharti W gawali }\end{array}$ & $\begin{array}{l}\text { With the help of RS, GIS and GPS technology there is an } \\
\text { enhancement in agriculture production. }\end{array}$ & 2016 \\
\hline 15 & $\begin{array}{l}\text { K. Lakshmisudha et } \\
\text { al }\end{array}$ & $\begin{array}{l}\text { WSN Algorithm were used in the fields to enhance optimal growth } \\
\text { conditions of plants and data accessible throughout the world. }\end{array}$ & 2016 \\
\hline 16 & $\begin{array}{l}\text { BhagyashreeK.Chate } \\
\text { and Prof.J.G.Rana }\end{array}$ & $\begin{array}{l}\text { The prototype developed with the help of raspberry pi module for } \\
\text { Android phones. }\end{array}$ & 2016 \\
\hline 17 & $\begin{array}{l}\text { Manikantan } \\
\text { Krishnaswamy } \\
\text { Ramakrishna et al }\end{array}$ & $\begin{array}{l}\text { Algorithm resolved the energy efficiency, cost efficiency and } \\
\text { accuracy issues by heavy economical systems integrated with GSM } \\
\text { module }\end{array}$ & 2016 \\
\hline 18 & $\begin{array}{l}\text { Suprabha Jadhav and } \\
\text { Shailesh Hambarde }\end{array}$ & $\begin{array}{l}\text { Prototype developed for automated irrigation system with the help of } \\
\text { raspberry pi which led to a decrease in and cost effective for } \\
\text { agriculture production. }\end{array}$ & 2016 \\
\hline 19 & $\begin{array}{l}\text { Deep Mala and } \\
\text { Dr.Suhas H.Patil }\end{array}$ & $\begin{array}{l}\text { Wireless sensor network(WSN) in agricultural monitoring at remote } \\
\text { sites }\end{array}$ & 2016 \\
\hline
\end{tabular}




\section{CONCLUSION}

Agriculture forms the backbone of most of the developing countries; agriculture methods with smart algorithms need to be implemented to meet current and future requirements of crops. Smart agriculture utilizes technology to limit resources and to increase productivity of crops in safe and secure environment. This paper presented a theoretic review on diversified methods for implementing smart agriculture by monitoring and control of diseases in sugarcane and corn, further a system model is presented that integrates ideal parameter monitoring through wireless sensor network along with image processing algorithms for early and automated detection of diseases that might infect the crop.

\section{REFERENCES}

[1] Aakash G Ratkal, Gangadhar Akalwadi, Vinay N Patil and Kavi Mahesh, "Farmer's Analytical Assistant” IEEE,CCEM.2016.22 978-1-5090-4573$0 / 16 \$ 31.00,2016$

[2] Kshitij Shinghal, Dr. Arti Noor, Dr. Neelam Srivastava and Dr. Raghuvir Singh, "Intelligent Humidity Sensor for - Wireless Sensor network Agricultural Application" IJWMN, Vol. 3, No. 1,pp 118-128,2011

[3] Wagner Fernando da Silva, Daniel Alves de Aguiar, Bernardo Friedrich Theodor Rudorff and Luciana Miura Sugawara, "Canasat Project:Monitoring of the Sugarcane Cultivation Area in South Central Brazil”, IAPRS, Vol. XXXVIII, Part 7B,pp 535-540,2010

[4] Manikantan Krishnaswamy Ramakrishna, Priya Prakash Parab, Puneet Girish Durve and Rahul Ashim De, "An Economical Wireless Sensor Network Based Solution for Precision Agriculture", Capstone Research Project Proposal,pp 1-10,2016

[5] Vaibhavi S. Bharwad and Kruti J. Dangarwala, "Recent Research Trends of Plant Disease Detection”,IJSR, Volume 4 Issue 12,pp 843-845,2015

[6] Ruchika Sharma and Sushma Tamta, "A Review on Red Rot: The "Cancer" of Sugarcane," JPPM,ISSN:2157-7471,2015

[7] Umapathy Eaganathan, Dr.Jothi Sophia, Vinukumar Luckose and Feroze Jacob Benjamin, "Identification of Sugarcane Leaf Scorch Diseases using Kmeans Clustering Segmentation and K-NN based Classification”, IJACST, Vol.3 , No.12, Pages :11-16,2014

[8] Ruchika and Ruchi Taneja, "Smart Agriculture Monitoring Through IOT (Internet of Things)”,IJSRD, Vol. 3, Issue 05, pp 817-819,2015

[9] Dr.D.Devi Aruna, “A Survey on Different Disease and Image Processing Techniques in Sugarcane Crops”,IJSRD, Vol. 3, Issue 11, pp 323-325,2016

[10] Bhagyashree K.Chate and Prof.J.G.Rana, "Smart Irrigation system using Raspberry pi”, IRJET,Volume: 03 Issue: 05,pp 247-249,2016

[11] K. Lakshmisudha, Swathi hedge, Neha kale and Shruti Iyer, "Smart Precision based Agriculture using Sensors",IJCA, Volume 146,No.11,pp 36-38, 2016

[12] Suprabha Jadhav and Shailesh Hambarde, “Android based Automated Irrigation System using Raspberry Pi”,IJSR, Volume 5,Issue 6,pp 23452351,2016

[13] Anjum Awasthi and S.R N Reddy, "Monitoring for precision Agriculture using wireless sensor network-A Review",GJCST, Volume 13,Issue 7, ISSN: 0975-4172,2013

[14] Amol D. Vibhute and Dr. Bharti W. Gawali, “Analysis and Modeling of Agricultural Land use using Remote Sensing and Geographic Information System: a Review”,IJERA, Vol. 3, Issue 3,pp.081-091,2013

[15] G.T.Hariharan, G.P.S.Hariharan and R Vijay Anandh, “Crop disease identification using image processing”,IJLTET,Vol 6,Issue 4,pp 255-259,2016

[16] Andrés Fernando Jiménez López, Juan Mauricio Salamanca, Melanie Jisell Quiroz Medina and O. E. Acevedo Pérez, “Crops Diagnosis Using Digital Image Processing and Precision Agriculture Technologies",INGE CUC, vol. 11 no. 1, pp 63-71,2015

[17] N. Sakthipriya, “An Effective Method for Crop Monitoring Using Wireless Sensor Network”, Middle-East Journal of Scientific Research, ISSN 19909233,pp 1127-1132,2014

[18] Kirankumar Y. Bendigeri and Jayashree D. Mallapur, "Advanced remote monitoring of a crop in agriculture using wireless sensor network topologies ”, IJECET, Volume 6, Issue 9, pp. 30-38,2015

[19] Deep Mala and Dr.Suhas H.Patil, "Role of Wireless Sensor Networks in Agriculture”,IJITE, Vol.04,Issue-05,pp 36-41,2016

[20] Abbass, El_Hag and A.M.H, “Crop Assessment and Monitoring for Sugar Cane Crop, Sudan, (New Halfa Case Study) Using Remote Sensing and GIS Techniques”,IJRSP, Volume 3, Issue 3,pp 1-10,2013

[21] Aleksandar Milenkovic, Chris Otto and Emil Jovanov, "Wireless sensor network for personal health monitoring:Issues and an implementation", Computer communication article, 2006

[22] Sudhanshu Sekhar Panda, Daniel P. Ames and Suranjan Panigrahi, “Application of Vegetation Indices for Agricultural Crop Yield Prediction Using Neural Network Techniques”,Remote sensing journal, ISSN 2072-4292,pp 673-696,2010

[23] Saleemmaleekh Attar and Sudhakar K N, "Real-Time Monitoring Of Agricultural Activities Using Wireless Sensor Network",IJSR, Volume 4 Issue 5, pp 2843-2846,2015

[24] D. Mahesh Kumar, "Healthcare Monitoring System Using Wireless Sensor Network”,IJANA, Volume:04,Issue:01,pp 1497-1500,2012

[25] Tushar H. Gore, Mayuri P. Kote, Parmeshwari B. Varpe and Prof. M. T. Jagtap, “Crop Monitoring Analysis and Controlling System”, IJARCSSE, Volume 6, Issue 2,pp 138-141,2016

[26] Meeradevi, Monica R Mundada and Nikhita, "Real Time Monitoring of Environmental Parameters in Precision Agriculture using Wireless Sensor Network", IICT, Volume 6 No. 8, ISSN 2223-4985,2016 